Eugênio Camargo Bruck, engenheiro agrônomo (UFRJ).

Hélio Yassurride Ono, engenheiro agrônomo (UnB).

Huyghens Caetano da Fonseca, engenheiro florestal (UnB)

Naírio Serpa Simões, médico veterinário

(UFRJ)

Mércia Maria Diniz, bióloga, mestre em fisioecologia pelo Instituto de Biociências da

USP. São, respectivamente, técnicos das coordenações de Áreas de Proteção Ambiental e de Estações Ecológicas da SEMA.
Eugênio Camargo Bruck

Hélio Yassurride Ono

Huyghens Caetano da Fonseca

Magna Leite Luduvice

Mércia Maria Diniz

Naírio Serpa Simões

\title{
Unidades de conservação
}

\section{Introdução}

Historicamente, a conservação de territórios, em especial a proteção à fauna em nosso continente, é anterior à vinda dos primeiros europeus.

Existem referências à civilização pré-hispânica inca - organizadas com seu governo central - que instituíram as primeiras atividades de preservação de animais registradas na história do continente.

Foram protegidas, nessa época, a gaivota, como também alguns animais produtores de carne ou lã, como vicunhas e guanacos. A caça em todo o império inca, o que hoje corresponderia a uma faixa desde o Equador ao centro do Chile, foi proibida por lei, com infrações punidas com pena de morte (Wetterberg, 1977). Havia, o que hoje denominamos de manejo de fauna.

Com a vinda dos espanhóis, o conservacionismo estabelecido pela civilização inca foi deixado de lado. Tem-se notícia das Leis das Índias do Século $X V I$ que visaram a proteção da flora e fauna do novo mundo, no entanto, esses regulamentos nunca foram cumpridos.

Os princípios da proteção à natureza foram conhecidos no Brasil na época colonial pela Carta Régia, de 13 de maio de 1797, que designou o então governador da Capitania de Paraíba, a "tomar todas as precauções para preservar as florestas no Estado do Brasil, e evitar a sua destruição... estabelecendo penas severas contra as pessoas que queimam ou destroem as florestas de outras maneira."

Contudo, os colonizadores portugueses, interessados na exploração dos recursos naturais no Brasil, tiveram, aparentemente, pouca consideração com espécies nativas de plantas e animais.

Já em 1825, Simón Bolivar proibiu a caça de vicunha no Peru, não sendo, porém, obedecido, devido à falta de controle e o alto valor da lã desses animais.

Somente a partir de 1876 é que reiniciam-se as atividades de preservação da natureza no continente, com a proposição, por André Rebouças, da criação de dois parques nacionais. Contudo, o primeiro parque naciónal no Brasil, Itatiaia, só veio a ser criado em 1937. Foi o parque nacional a primeira categoria de manejo de unidades de conservação.

\section{Unidades de conservação}

As unidades de conservação são áreas protegidas, estabelecidas em ecossistemas significativos do território nacional, nesse caso pelo governo federal, bem como em cada uma das unidades da Federação pelos respectivos governos estaduais, $e$ 
mesmo municipais em seu âmbito administrativo. Têm a finalidade de:

- preservar bancos genéticos, de fauna e flora, de modo a permitir pesquisas que levam à utilização racional pelo homem. O estudo das espécies florísticas e faunísticas nos seus habitats naturais conduzem ao manejo adequado da fauna. As partes de pesquisas adequadas podem-se estabelecer, por exemplo, criatórios de jacarés, capivaras, ratão de banhado, etc. O mesmo procedimento é cabível à flora, com significância em trabalhos genéticos para aperfeiçoamento de variedades comerciáveis, estudos farmacológicos, etc;

- acompanhar, no entorno e nas áreas protegidas, através do monitoramento ambiental, as alterações que ocorrem, tanto provocadas por uma ação antrópica quanto natural, correlacionando as mudanças externas às áreas, que ocorrem de maneira mais impactante, com as mudanças internas, estabelecendo-se parâmetros para melhor conduzir o uso do solo ou reabilitar áreas que já estejam degradadas;

- proteger os recursos hídricos, em especial as cabeceiras de rios e áreas, ao longo das bacias hidrográficas que apresentam pressão demográfica;

- proteger paisagens de relevante beleza cênica, bem como aquelas que contenham valores culturais, históricos e arqueológicos com finalidades de estudos e turismo;

- conduzir de maneira apropriada a educação ambiental, tanto de cunho turístico quanto ligada a atividades escolares;

- proporcionar, através de bases físicas nas unidades de conservação, condições para o desenvolvimento de pesquisas que poderão ser desde observações até alterações do ecossistema. Os produtos das pesquisas têm a finalidade de atender a toda região de ecossistema homogêneo no désenvolvimento racional das atividades do homem;

- proteger áreas de particulares que tenham relevantes interesses faunístico elou florístico;

- proteger áreas que venham a ter, no futuro, uma utilização racional do uso do solo.

\section{Unidades de conservação existentes}

As categorias de manejo existentes no país, implantadas pelo governo federal, são, até o momento: os parques nacionais; as reservas biológicas; as reservas florestais, aos cuidados do Instituto Brasileiro de Desenvolvimento Florestal - IBDF, tendo sob a administração do Instituto Brasileiro de Geografia e Estatística - IBGE, também reservas biológicas; as reservas indígenas, sob administração da Fundação Nacional do Índio - Funai; o monumento cultural, sob administração da Secretaria do Patrimônio Histórico e Artístico Nacional - SPHAN; as estações ecológicas; áreas de proteção ambien- tal e as reservas ecológicas, sob administração da Secretaria Especial do Meio Ambiente - SEMA.

Os governos estaduais e municípios têm, por lei, condições de criar unidades de conservação. Encontramos, no nível estadual, já implantados, parques estaduais e reservas biológicas, bem como áreas de proteção ambiental, sendo a de Corumbataí a primeira criada em nível estadual, em São Paulo. Nada impede, também, que a nível estadual e municipal sejam criadas estações ecológicas.

A Lei n. 6.902, de 27 de abril de 1981, que dispõe sobre a criação de estações ecológicas, áreas de proteção ambiental e dá outras providências, trouxe a base para criação dessas unidades.

\section{Estações ecológicas}

$\mathrm{O}$ artigo da referida lei define as estações ecológicas como "áreas representativas de ecossistemas brasileiros destinadas à realização de pesquisas básicas e aplicadas de ecologia, à proteção do ambiente natural e ao desenvolvimento da educação conservacionista."

No entanto, o que melhor caracteriza e o que torna ímpar tais áreas está nos parágrafos $11^{\circ}$ e $22^{\circ}$ do art. 1. , onde preceitua que " $90 \%$ ou mais da área de cada estação ecológica será destinada, em caráter permanente, e definida em ato de poder executivo, à preservação integral da biota, na área restante, desde que haja um plano de zoneamento aprovado, segundo se dispuser em regulamento, poderá ser autorizada a realização de pesquisas ecológicas que venham a acarretar modificações no ambiente natural."

Vê-se que o zoneamento das estações ecológicas é de fundamental importância na organização espacial, possibilitando, concomitantemente, a conservação de áreas mais frágeis e a definição de áreas destinadas às pesquisas, administração e experimentações. Isto posto, a organização dos espaços permite que a estação ecológica dê prosseguimento, em sua plenitude, ao programa de pesquisas.

Para a escolha de áreas que venham a integrar a rede de estações ecológicas, utiliza-se como critério básico os "domínios morfoclimáticos e regiões fitogeográficas do Brasil" descritos por Aziz $A b^{\prime}$ Saber.

\section{Localização}

Para o desenvolvimento do Programa de Estações Ecológicas, a SEMA vem recebendo o apoio integral de universidades e outras instituições de pesquisas e oferece, ao mesmo tempo, condições para 
que os mesmos possam ampliar e aperfeiçoar os recursos materiais e humanos de que dispõem.

Como foi mencionado anteriormente, esse tipo de unidade de conservação está sendo estabelecido em várias regiões do país.

Para caracterizar os grandes ecossistemas brasileiros, de modo que cada área escolhida seja representativa de uma fatia maior do território, utiliza-se a classificação de Aziz Ab'Saber, que tem como base os domínios morfoclimáticos. Entende-se o domínio morfoclimático e fitogeográfico como um conjunto espacial de certa ordem de grandeza territorial de centenas de milhares a milhões de $\mathrm{km}^{2} \mathrm{de}$ área, onde haja um esquema coerente de feições de relevo, tipos de solos, formas de vegetação e condições climático-hidrológicas.

Segundo esse autor, podem ser reconhecidos, até o momento, seis grandes domínios paisagísticos e macroecológicos em nosso país. Quatro deles são intertropicais, cobrindo uma área pouco superior a 7 milhões de $\mathrm{km}^{2}$, os outros dois, subtropicais,

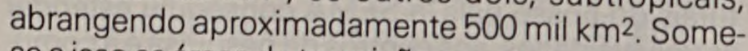
se a isso as áreas de transição e contato que equivalem a mais ou menos 1 milhão de $\mathrm{km}^{2}$. Dentro desses domínios pode-se encontrar diferenciações fisionômicas, graças a uma heterogeneidade do relevo, solos, vegetação, etc.

Daremos, a seguir, a relação das estações ecológicas e suas localizações em relação aos grandes domínios propostos por Ab'Saber.

\section{Domínio das terras baixas florestadas da Amazônia}

Abrange mais de 2 milhões de $\mathrm{km}^{2}$, com predominância de floresta pluvial densa, possuindo elevadas temperaturas e alta umidade relativa do ar.

Nesse domínio temos: Estação Ecológica de Anavilhanças, situada no Rio Negro, a montante de Manaus; Estação Ecológica de Maracá-AP, ilhas marítimas situadas nas costas do Território do Amapá; Estação Ecológica do Acre, situada no Estado do Acre, nas cabeceiras do rio de mesmo nome; Estação Ecológica de Juami-Japurá, abrangendo toda a bacia do Rio Juami, afluente do Rio Japurá; Estação Ecológica do Jari, localizada ao norte do Estado do Pará, próximo a cidade de Monte Dourado; Estação Ecológica de Cuniã, localizada às margens do Rio Madeira, no Estado de Rondônia; mais ao norte, no Território Federal de Roraima, numa área de transição do domínio Amazônico com os campos de Roraima temos as estações ecológicas de Caracaraí e Maracá (RR); em outra área de transição com o domínio Amazônico e o domínio de cerrados, encontra-se a Estação Ecológica de lquê-Juruena, situada a noroeste do Estado de Mato Grosso; aí, também, encontra-se a Estação Ecológica de UruçuiUna, situada em uma área de transição entre os domínios do cerrado e da caatinga, localizada no sul do Estado do Piauí.

\section{Domínio das depressões intermontanas e interplanálticas semi-áridas do Nordeste}

Com uma superfície variando entre 700 a 850 mil km², possui regiões de várzeas e os denominados vales úmidos e apresenta precipitações pluviométricas baixas e irregularmente distribuídas, com anos secos. Nessa região, é característica uma paisagem de vegetação arbustiva, espinhosa, caducifólia, com os famosos mandacarus.

Situam-se nesse domínio: Estação Ecológica de Aiuaba, situada no sul do Estado do Ceará; Estação Ecológica do Seridó, situada no sudoeste do Estado do Rio Grande do Norte; Estação Ecológica do Raso da Catarina, situada ao norte do Estado da Bahia, nas proximidades da cidade de Paulo Afonso; situada em uma área de transição entre a caatingá e o domínio dos mares de morro, abrangendo ecossistemas de matas rupestres, matas de galeria e tabuleiros, temos a Estação Ecológica de Itabaiana no Estado de Sergipe.

\section{Domínio dos "mares de morros" florestado}

Tem uma extensão aproximada de 650 mil $\mathrm{km}^{2}$, caracterizada por uma floresta tropical atlântica, distribuindo-se ao longo da costa brasileira. Possui enclaves de bosques de araucárias e de cerrados em diversos compartimentos dos planaltos interiores.

Nesse domínio estão localizadas: Estação Ecológica de Mamanguape, situada no litoral do Estado da Paraíba; Estação Ecológica da Praia do Peba, localizada no Estado de Sergipe, próxima à foz do Rio São Francisco; Estação Ecológica de Tamoios, situada no litoral do Estado do Rio de Janeiro; Estação Ecológica de Piraí, localizada no litoral do Estado do Rio de Janeiro; Estação Ecológica de Juréia, localizada no litoral sul do Estado de São Paulo; Estação Ecológica de Guaraqueçaba, no litoral paranaense; Estação Ecológica de Carijós, próxima à cidade de Florianópolis no Estado de Santa Catarina. 


\section{Domínio dos chapadões tropicais interiores recobertos por cerrados e penetrados por floresta galeria}

A superfície aproximada desse domínio é de 1,8 milhão de $\mathrm{km}^{2}$, onde encontra-se uma vegetação típica com árvores tortuosas, de solos ácidos e pobres em minerais, embora apresentando boa estrutura física. Al ocorre, também, a vegetação de mata galeria ou mata ripária, com vegetação de porte mais elevado com indivíduos de fuste retilíneo, desenvolvendo-se ao longo dos cursos d'água. Possui precipitação pluviométrica elevada no verão e bastante reduzida no inverno.

Nesse domínio estão localizadas: Estação Ecológica de Parapitinga, ilha lacustre, formada após o represamento do Rio São Francisco com a barragem de Três Marias, no Estado de Minas Gerais; Estação Ecológica de Coco-Javaés, próximo a llha do Bananal, às margens do Rio Araguaia, no Estado de Goiás; Estação Ecológica de Serra das Araras, localizada em uma área de transição do domínio de cerrados, próximo ao Pantanal Mato-Grossense, no Estado de Mato Grosso; ainda em uma faixa de transição, desta feita, já no interior do complexo.do Pantanal MatoGrossense, situa-se a Estação Ecológica de Taiamã, no Estado de Mato Grosso.

\section{Domínio dos planaltos subtropicais com araucárias}

Localizada praticamente na Região Sul do país, com uma superfície de aproximadamente 400 mil $\mathrm{km}^{2}$, possui climas subtropicais úmidos, com distribuição das chuvas de forma mais ou menos constante durante $\mathrm{o}$ ano inteiro. A marca fundamental dessa paisagem era representada pelos grandes pinheirais, que estão sendo dizimados implacavelmente.

Nesse domínio temos: Estação Ecológica de Aracuri-Esmeralda, localizada ao norte do Estado do Rio Grande do Sul, próximo a cidade de Vacaria; ainda em terras gaúchas, situada na região de planície dos grandes lagos; junto ao litoral, entre o oceano e a Lagoa Mirim, temos a Estação Ecológica do Taim.

\section{Domínio das coxilhas subtropicais com pradarias mistas}

A área é de aproximadamente $80 \mathrm{mil} \mathrm{km²}^{2}$ com denominação usual de Campanha Gaúcha, também popularmente de Região dos Pampas, situada no território nacional no Estado do Rio Grande do Sul.
Esse domínio, o menor de todos, não poderia deixar de ser mencionado, como parte integrante e final da classificação morfoclimática de Ab'Saber, embora não conste nela nenhuma estação ecológica.

Até aqui, procurou-se mostrar em rápidas pinceladas os cuidados que a SEMA vem tomando na escolha de áreas que integram a rede de estações ecológicas, e que são representativas dos grandes ecossistemas.

Observa-se porém, que essa rede estender-seá, na medida da existência dos denominados subdomínios, de modo a abarcar a maior representatividade possível dos ecossistemas brasileiros, em seus diversos graus de dimensões.

\section{Pesquisas nas estações ecológicas}

Com o estabelecimento do Programa de Estações Ecológicas nos mais variados ecossistemas naturais do nosso país, a SEMA conseguiu estender às universidades, aos centros de pesquisa eà comunidade científica, condições necessárias para o desenvolvimento de estudos e pesquisas que visam obter informações úteis ao planejamento regional e o aproveitamento racional dos recursos naturais.

Os projetos de pesquisas, por parte dessas entidades ou pesquisadores isolados, são elaborados em conformidade com os critérios prioritários adotados: levantamento dos fatores físicos; levantamento dos fatores bióticos; monitoramento; pesquisas propriamente ditas.

Determina a Lei n. 6.902 , nos artigos $1^{\circ}$ e e $3^{\circ}$, que "as pesquisas científicas e outras atividades realizadas nas estações ecológicas, levarão sempre em conta a necessidade de não colocar em perigo a sobrevivência das populações das espécies ali existentes".

Com a apresentação dos projetos de pesquisas à SEMA, esses, são submetidos a uma análise e selecionados segundo uma comissão técnica multidisciplinar, ficando a sua execução sujeita à fiscalização e acompanhamento técnico.

Além da SEMA, como agente gerenciador, e as entidades executoras dos projetos de pesquisas, participam nesse programa outros órgãos ou entidades nacionaislestrangeiras, que apóiam financeiramente a execução de pesquisa no Brasil. Este apoio se refere a bolsas de formação (iniciação e aperfeiçoamento), bolsaslauxílios à pesquisa e financiamento, quando dele se fizer necessário.

Ao final da execução do projeto de pesquisa, é apresentado o relatório final, constando resultados, 
que é passível de publicação por parte da SEMA, dependendo da sua importância.

\section{Base física de uma estação ecológica}

A finalidade básica de uma estação ecológica é a de preservar o ecossistema em que se encontra, bem como proporcionar infra-estrutura física para o desenvolvimento de pesquisas na área.

Essa infra-estrutura, que a SEMA coloca à disposição de todos os usuários das estações ecológicas, consta de: alojamento com capacidade para aproximadamente vinte pessoas; cozinha e refeitório; pequeno laboratório; casa da administração com escritório; casa do zelador; postos avançados de pesquisas, localizados em pontos estratégicos da área, que são utilizados para vigilância como também para abrigar pesquisadores que se afastam da sede; veículos de transporte, tanto terrestre como aquático, de acordo com as características da área; sistemas de comunicação, um de longo alcance, ligado com a sede central em Brasília, e outro de médio alcance utilizado para comunicação interna da área.

\section{Áreas de proteção ambiental}

As Áreas de Proteção Ambiental - APA's, fazem parte do sistema de unidades de conservação da SEMA e são criadas com a finalidade de assegurar o bem-estar das populações humanas e conservar ou melhorar as condições ecológicas locais.

É uma unidade de conservação nova no Brasil, mas já existente em alguns países da Europa, como Alemanha e Portugal, com o nome de parque natural.

Nestas áreas não é feita a desapropriação, podendo, então, serem compostas de terras da União ou particulares. As atividades culturais locais ou regionais nelas desenvolvidas são mantidas, sendo proposto, apenas, o disciplinamento do uso do solo.

É necessário haver integração e interesse da população pela conservação da área, sendo de vital importância a educação ambiental para todos os níveis de escolaridade e a divulgação dos benefícios que uma área de proteção ambiental pode trazer para a população local.

Foram estabelecidas normas para as áreas de proteção ambiental, pela Lei . $^{\circ} 6.902$, limitando ou proibindo a implantação e o funcionamento de indústrias potencialmente poluidoras, capazes de afetar mananciais de água; a realização de obras de terraplanagem e a abertura de canais, quando essas iniciativas importarem em sensível alteração das condições ecológicas locais; o exercício de atividades capazes de provocar uma acelerada erosão das ter- ras elou um acentuado assoreamento das coleções . hídricas; o exercício de atividades que ameaçam extinguir na área protegida as espécies raras da biota regional.

As áreas de proteção ambiental são criadas por meio de decreto federal assinado pelo presidente da República, com exposição de motivos elaborada pelo ministro de Estado do Interior que, por sua vez, recebe do secretário especial do Meio Ambiente a proposta de criação.

Na seleção das áreas para a implantação de uma APA, vários fatores são levados em consideração, tais como: cobertura vegetal significativa; existência de encostas passíveis de erosão; presença de solos excepcionalmente férteis, quando passíveis de utilização para a agricultura; existência de monumentos naturais; existência de espécies raras de biota regional; constatação de endemismos, etc.

Após a seleção daárea, serão indicados nomes de representantes de entidades públicas e privadas para compor um grupo executivo responsável pela realização dos estudos preliminares, sob coordenação da SEMA.

Estes estudos serão compostos de: delimitação da área, utilizando, na medida do possível, os limites naturais e artificiais notadamente visíveis; levantamento de dados existentes sobre a área; situação fundiária, clima, relevo e geomorfologia, solos (classes de uso do solo), hidrografia, flora, fauna, ocorrência de endemismos e espécies em extinção; justificativas evidenciando da melhor maneira possível a criação da APA.

Nas áreas de proteção ambiental é preponderante o zoneamento, que consiste em detectar a meIhor aptidão das diversas áreas de uma região. O zoneamento tem como objetivo restringir ou incentivar a utilização do solo, visando a manter atividades racionais compatíveis com as necessidades de proteção do meio ambiente.

A APA pode disciplinar, não só o uso do solo, como também o de cursos d'água e áreas costeiras.

Nas APA's, é imprescindivel a.criação de uma "zona de vida silvestre", que deverá permanecer praticamente intocada, protegendo assim as espécies vegetais e animais consideradas raras na biota regional. Essa zona, merecedora de especial atenção, poderá sobrepor-se às reservas ecológicas láreas de preservação permanente, Código Florestal, Lei n. 4.771, de 15 de setembro de 1965).

O żoneamento poderá ser feito pelo grupo executivo ou não, ficando a critério da SEMA sobre a melhor maneira de executá-lo.

Os estudos referentes à criação de uma APA 
objetivam também verificar os problemas de ocupação humana (urbanização), propondo medidas para compatibilizar tais atividades com a proteção ambiental.

Para a fiscalização das APA's, além da representação estadual da SEMA, serão celebrados convênios com entidades públicas ou privadas com sede no Estado em que se encontram. Existe também um programa de repasse de bolsas de estudo da Coordenação do Aperfeiçoamento de Pessoal de Nível Superior - CAPES e do Conselho Nacional de Desenvolvimento Científico e Tecnológico - CNPq, visando integrar esforços de interesse promovendo um fluxo periódico de informações sobre a área.

Encontram-se em estudo oito APA's, sendo elas: Guapi-Mirim, Cairuçu e Tamoios, no Estado do Rio de Janeiro; Cananéia-I guape, no Estado de São Paulo; Guaraqueçaba, no Paraná; Mantiqueira, nos estados de São Paulo, Rio de Janeiro e Minas Gerais; Rio São Bartolomeu e Rio Descoberto, no Distrito Federal.

Duas APA's a nível federal já foram decretadas: Petrópolis, no Rio de Janeiro, e Piaçabuçu, em Alagoas.

Convém destacar que para manter essas áreas íntegras não basta tão-somente manter ativo um sistema de vigilância, deixando alijadas do processo as comunidades existentes no entorno.

É de fundamental importância o desenvolvimento de todo um programa de educação ambiental de maneira que haja uma consciência de que as áreas protegidas afetarão as comunidades, positivamente, por gerações.

\section{Estações ecológicas já implantadas}

\begin{tabular}{|c|c|c|c|}
\hline \multirow{2}{*}{ Estações ecológicas } & \multicolumn{2}{|c|}{ Localização } & \multirow{2}{*}{$\mathrm{HA}$} \\
\hline & Latitude & Longitude & \\
\hline $\begin{array}{l}\text { Taim (RS) } \\
\text { Esmeralda (RS) } \\
\text { Juréia (SP) } \\
\text { lguê (MT) } \\
\text { Taiamã (MT) } \\
\text { Anavilhanas (AM) } \\
\text { Maracá (RR) } \\
\text { Maracá (AP) } \\
\text { Raso da Catarina (BA) } \\
\text { Aiuaba (CE) } \\
\text { Uruçui-Una (PI) }\end{array}$ & $\begin{array}{r}32^{\circ} 32 / 32^{\circ} 50^{\prime} \\
28^{\circ} 12^{\prime} / 28^{\circ} 14^{\prime} \\
24^{\circ} 25^{\prime} / 24^{\circ} 35^{\prime} \\
11^{\circ} 30^{\prime} / 12^{\circ} 02^{\prime} \\
16^{\circ} 50^{\prime} 16^{\circ} 57^{\prime} \\
2^{\circ} 00^{\prime} 3^{\circ} 02^{\prime} \\
3^{\circ} 15^{\prime} \prime 3^{\circ} 35^{\prime} \mathrm{N} \\
1^{\circ} 50^{\prime} \prime 2^{\circ} 15^{\prime} \mathrm{N} \\
9^{\circ} 20^{\prime} 9^{\circ} 55^{\prime} \\
6^{\circ} 35^{\prime} / 6^{\circ} 41^{\prime} \\
8^{\circ} 37^{\prime} / 9^{\circ} 10^{\prime}\end{array}$ & $\begin{array}{r}52^{\circ} 23^{\prime} / 52^{\circ} 32^{\prime} \\
51^{\circ} 10^{\prime} 51^{\circ} 11^{\prime} \\
47^{\circ} 00^{\prime} / 47^{\circ} 15^{\prime} \\
58^{\circ} 42^{\prime} / 59^{\circ} 53^{\prime} \\
57^{\circ} 23^{\prime} / 57^{\circ} 28^{\prime} \\
60^{\circ} 27^{\prime} / 61^{\circ} 07^{\prime} \\
61^{\circ} 22^{\prime} / 61^{\circ} 58^{\prime} \\
50^{\circ} 17^{\prime} 57^{\circ} 40^{\prime} \\
38^{\circ} 29^{\prime} / 38^{\circ} 43^{\prime} \\
40^{\circ} 07^{\prime} / 40^{\circ} 20^{\prime} \\
44^{\circ} 55^{\prime} / 45^{\circ} 30^{\prime}\end{array}$ & $\begin{array}{r}32.000 \\
272 \\
30.000 \\
200.000 \\
12.000 \\
350.000 \\
92.000 \\
70.000 \\
200.000 \\
13.000 \\
135.000\end{array}$ \\
\hline
\end{tabular}

\section{Estações ecológicas em implantação}

\begin{tabular}{l|c|c|r}
\hline \multirow{2}{*}{ Estações ecológicas } & \multicolumn{2}{|c|}{ Localização } & \multirow{2}{*}{ HA } \\
\cline { 2 - 3 } & Latitude & Longitude & \\
\cline { 2 - 3 } & $10^{\circ} 40^{\prime} / 10^{\circ} 42^{\prime}$ & $37^{\circ} 25^{\prime} / 37^{\circ} 28^{\prime}$ & 3.000 \\
\hline Itabaiana (SE) & $6^{\circ} 40^{\prime} 7^{\circ} 20^{\prime}$ & $34^{\circ} 40^{\prime} / 35^{\circ} 20^{\prime}$ & 3.000 \\
Mamanguape (PB) & $6^{\circ} 35^{\prime} / 6^{\circ} 40^{\prime}$ & $37^{\circ} 20^{\prime} / 37^{\circ} 39^{\prime}$ & 3.500 \\
Seridó (RN) & $8^{\circ} 00^{\prime} / 8^{\circ} 10^{\prime}$ & $63^{\circ} 00^{\prime} 63^{\circ} 40^{\prime}$ & 100.000 \\
Cuniã (RO) & & & \\
Serra das Araras & $15^{\circ} 30^{\prime} / 16^{\circ} 00^{\prime}$ & $57^{\circ} 00^{\prime} / 57^{\circ} 30^{\prime}$ & 28.700 \\
(MT) & $22^{\circ} 40^{\prime} / 23^{\circ} 00^{\prime}$ & $43^{\circ} 50^{\prime} / 44^{\circ} 10^{\prime}$ & 4.000 \\
Piraí (RJ) & $18^{\circ} 15^{\prime} / 18^{\circ} 30^{\prime}$ & $45^{\circ} 10^{\prime} / 45^{\circ} 25^{\prime}$ & 10.000 \\
Parapitinga (MG) & $10^{\circ} 30^{\prime} / 11^{\circ} 00^{\prime}$ & $69^{\circ} 30^{\prime} / 71^{\circ} 00^{\prime}$ & 77.000 \\
Rio Acre (AC) & $00^{\circ} 19^{\prime} / 00^{\circ} 43^{\prime}$ & $52^{\circ} 43^{\prime} / 53^{\circ} 21^{\prime}$ & 200.000 \\
Jari (PA) & $01^{\circ} 30^{\prime} / 01^{\circ} 50^{\prime}$ & $61^{\circ} 05^{\prime} / 61^{\circ} 30^{\prime}$ & 80.000 \\
Caracarai (AM) & $25^{\circ} 10^{\prime} / 25^{\circ} 20^{\prime}$ & $48^{\circ} 10^{\prime} / 48^{\circ} 25^{\prime}$ & 13.640 \\
Guaraqueçaba(PR) & $27^{\circ} 00^{\prime} / 28^{\circ} 00^{\prime}$ & $48^{\circ} 00^{\prime} / 49^{\circ} 00^{\prime}$ & \\
Carijós (SC) & & & \\
& & & \\
\hline
\end{tabular}

\section{Estações ecológicas em estudo}

\begin{tabular}{l|r|r|r}
\hline \multirow{2}{*}{ Estações ecológicas } & \multicolumn{2}{|c|}{ Localização } & \multirow{2}{*}{ HA } \\
\cline { 2 - 3 } & Latitude & \multicolumn{1}{|c}{ Longitude } & \\
\hline Serra Geral (SC) & $28^{\circ} 40^{\prime} / 28^{\circ} 50^{\prime}$ & $49^{\circ} 40^{\prime} / 50^{\circ} 00^{\prime}$ & \multirow{2}{*}{8.000} \\
Tamoios (RJ) & $22^{\circ} 55^{\prime} / 23^{\circ} 15^{\prime}$ & $44^{\circ} 15^{\prime} / 44^{\circ} 45^{\prime}$ & \\
Praia do Peba (AL) & $10^{\circ} 20^{\prime} / 10^{\circ} 30^{\prime}$ & $36^{\circ} 15^{\prime} / 36^{\circ} 25^{\prime}$ & 3.000 \\
Coco-Javaés (GO) & $9^{\circ} 48^{\prime} / 10^{\circ} 27^{\prime}$ & $49^{\circ} 00^{\prime} / 50^{\circ} 07^{\prime}$ & 37.000 \\
Juami-Japurã & & & \\
\hline
\end{tabular}

\section{Bibliografia}

1. AB'SABER, Aziz Nacib. Potencialidades paisagísticas brasileiras. São Paulo, USP/IGEOG, 1977.

2. AREA de Proteção Ambiental. S. n. T. 1p.

3. BRASIL. Leis, decretos, etc. Política Nacional do Meio Ambiente; Lei n. 6.938 , de 31 de agosto de 1981. Brasília, SEMA, 1981, $11 \mathrm{p}$.

4. decretos, etc. Estações ecológicas e áreas de proteção ambiental; Lei n. 6.902, de 27 de abril de 1981. Brasília, SEMA, 1981.

5. DINIZ, Mércia. Uma nova unidade de conservação da Secretaria Especial do Meio Ambiente, área de protecão ambiental. In: CONGRESSO NACIONAL SOBRE ESSENCIAS NATIVAS. Campos de Jordão, 1982. Anais do Congresso Nacional sobre Essências Nativas. São Paulo, Secretaria de Agricultura e Abastecimento, 1982. p. 1804-5 (edição especial da revista Silvicultura em São Paulo).

6. RESUMO das áreas de proteção ambiental em estudo. S. n. t. 4p.

7. UMA NOVA UNIDADE de Conservação da Secretaria Especial do Meio Ambiente (APA) s. n. t. 4p.

8. WETTERBERG, G. B. Uma breve história de parques nacionais e atividades relacionadas com a proteção da natureza na América do Sul. In: Curso de Treinamento sobre Administração e Manejo de Parques Nacionais. Brasília, IBDF, 1977. 


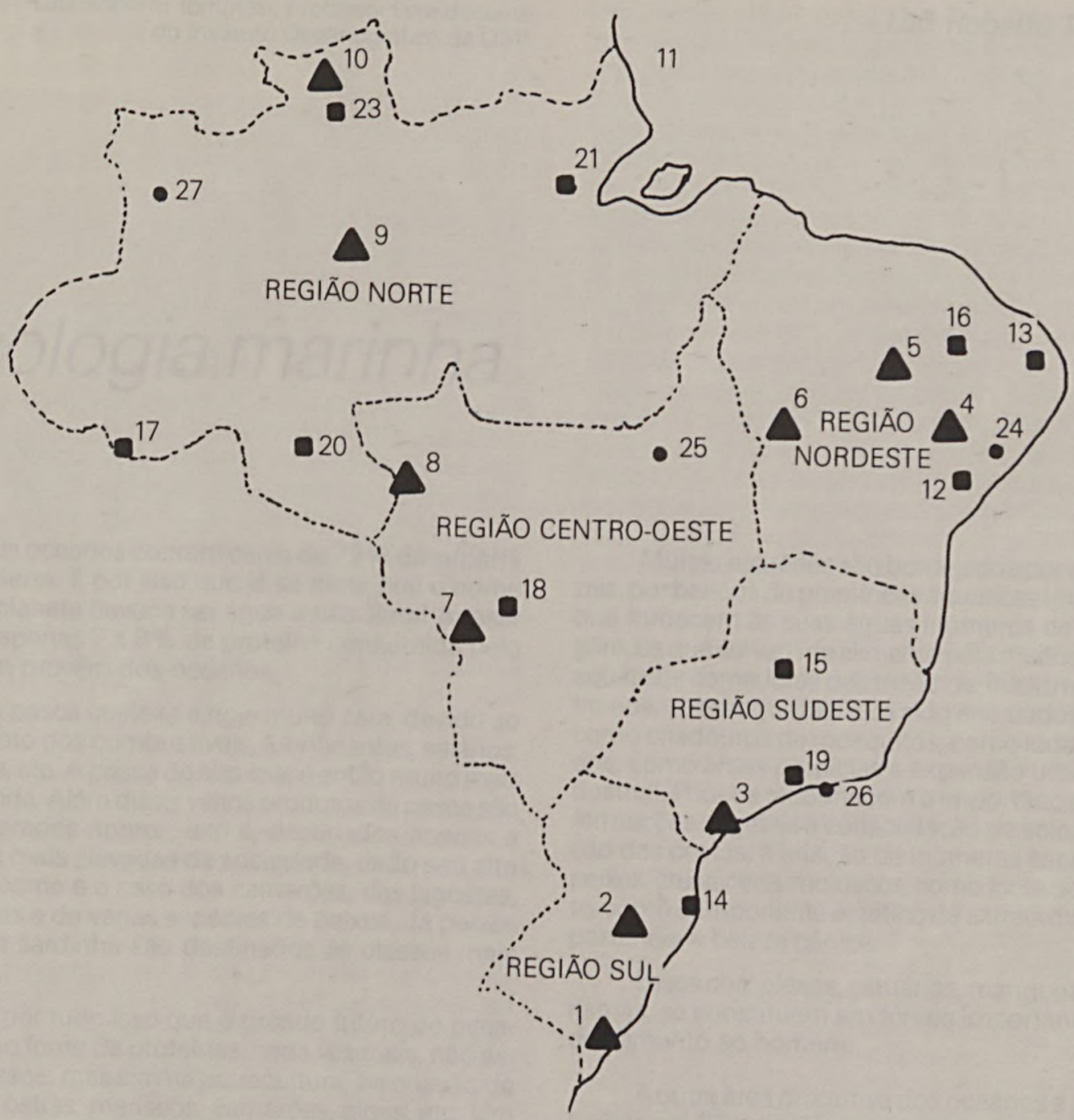

ESTAÇÕES ECOLOGICAS POR REGIÕES

\ Estações ecológicas implantadas

1 Taim (RS)

2 Aracuri Esmeralda (RS)

3 Juréia (SP)

4 Raso da Catarina (BA)

5 Aluaba (CE)

6 Uruçui-Una (PI)

7 Taiamã (MT)

Iquê-Juruena (MT)

9 Anavilhanas (AM)

10 Maracá (RR)

11 Maracá (AP)

- Estações Ecológicas em Implantação

12 Itabaiana (SE)

13 Mamanguape (PB)

14 Carijós (SC)

15 Parapitinga (MG)

16 Seridó (RN)

17 Rio Acre (AC)

18 Serra das Araras (MT)

19 Piraĺ (RJ)

20 Cuniã (RO)

21 Jari (PA)

22 Guaraqueçaba (PR)

23 Caracafaí (RR)

- Estações ecológicas em estudo

24 Praia do Peba (AL)

25 Coco-Javaés (GO)

26 Tamoios (RJ).

27 Juami-Japurá (AM) 


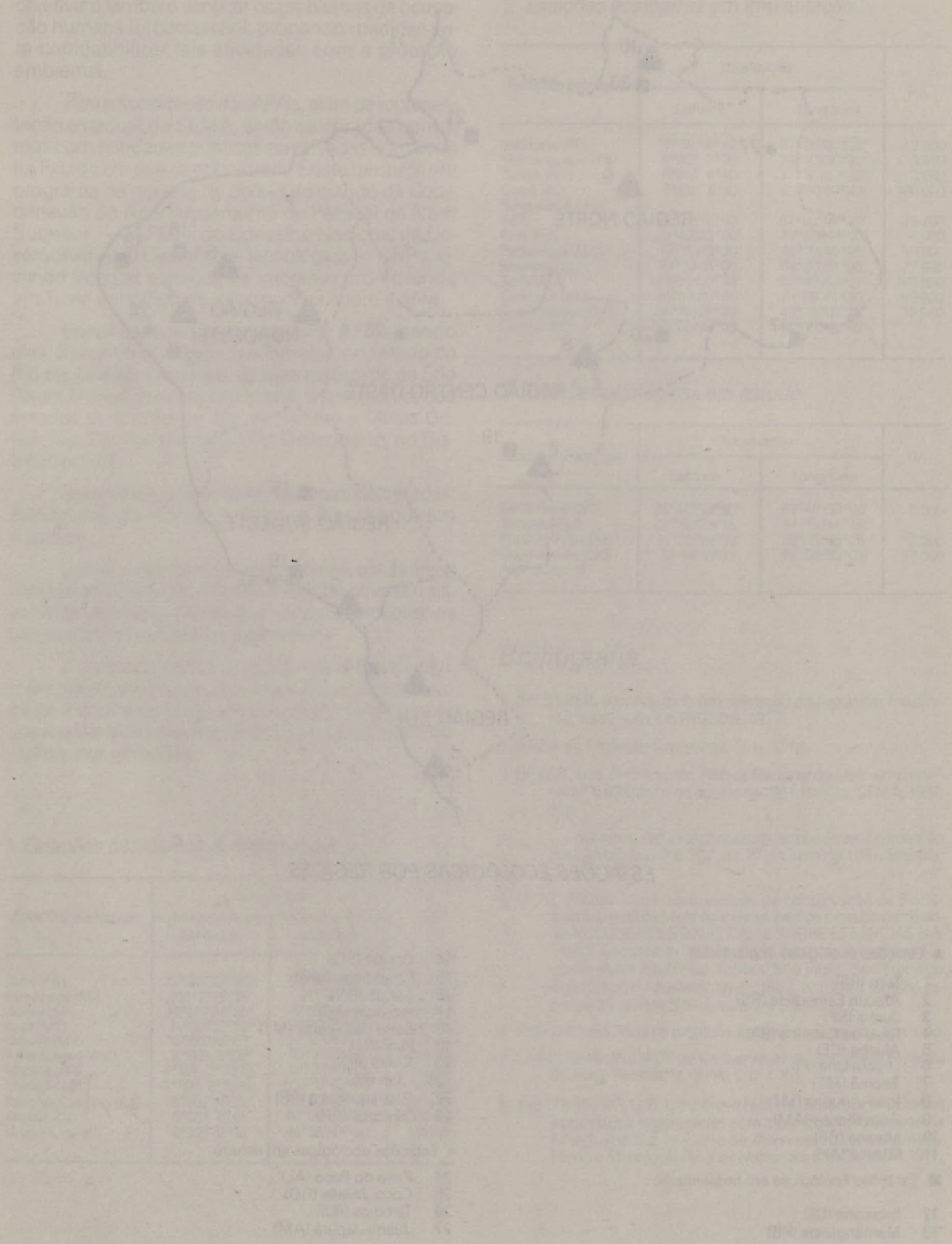

